NASA/TM-2003-212308

\title{
Quantification of Ice Accretions for Icing Scaling Evaluations
}

Gary A. Ruff

Glenn Research Center, Cleveland, Ohio

David N. Anderson

Ohio Aerospace Institute, Brook Park, Ohio 
Since its founding, NASA has been dedicated to the advancement of aeronautics and space science. The NASA Scientific and Technical Information (STI) Program Office plays a key part in helping NASA maintain this important role.

The NASA STI Program Office is operated by Langley Research Center, the Lead Center for NASA's scientific and technical information. The NASA STI Program Office provides access to the NASA STI Database, the largest collection of aeronautical and space science STI in the world. The Program Office is also NASA's institutional mechanism for disseminating the results of its research and development activities. These results are published by NASA in the NASA STI Report Series, which includes the following report types:

- $\quad$ TECHNICAL PUBLICATION. Reports of completed research or a major significant phase of research that present the results of NASA programs and include extensive data or theoretical analysis. Includes compilations of significant scientific and technical data and information deemed to be of continuing reference value. NASA's counterpart of peerreviewed formal professional papers but has less stringent limitations on manuscript length and extent of graphic presentations.

- TECHNICAL MEMORANDUM. Scientific and technical findings that are preliminary or of specialized interest, e.g., quick release reports, working papers, and bibliographies that contain minimal annotation. Does not contain extensive analysis.

- CONTRACTOR REPORT. Scientific and technical findings by NASA-sponsored contractors and grantees.
- CONFERENCE PUBLICATION. Collected papers from scientific and technical conferences, symposia, seminars, or other meetings sponsored or cosponsored by NASA.

- SPECIAL PUBLICATION. Scientific, technical, or historical information from NASA programs, projects, and missions, often concerned with subjects having substantial public interest.

- TECHNICAL TRANSLATION. Englishlanguage translations of foreign scientific and technical material pertinent to NASA's mission.

Specialized services that complement the STI Program Office's diverse offerings include creating custom thesauri, building customized databases, organizing and publishing research results ... even providing videos.

For more information about the NASA STI Program Office, see the following:

- Access the NASA STI Program Home Page at http://www.sti.nasa.gov

- E-mail your question via the Internet to help@sti.nasa.gov

- Fax your question to the NASA Access Help Desk at 301-621-0134

- Telephone the NASA Access Help Desk at 301-621-0390

- Write to:

NASA Access Help Desk

NASA Center for AeroSpace Information 7121 Standard Drive

Hanover, MD 21076 
NASA/TM-2003-212308

\section{Quantification of Ice Accretions for Icing Scaling Evaluations}

Gary A. Ruff

Glenn Research Center, Cleveland, Ohio

David N. Anderson

Ohio Aerospace Institute, Brook Park, Ohio

Prepared for the

36th Aerospace Sciences Meeting and Exhibit

sponsored by the American Institute of Aeronautics and Astronautics

Reno, Nevada, January 12-15, 1998

National Aeronautics and

Space Administration

Glenn Research Center 


\section{Acknowledgments}

This work was partially supported by NASA Glenn Research Center through grant NAG3-2043. The authors wish to thank Catherine Miller and Mark Nadzadi for their assistance in measuring the ice accretions and to

Chris Anthony for demonstrating the performance of fuzzy inference system when applied to ice accretion measurements.

The Propulsion and Power Program at NASA Glenn Research Center sponsored this work.

Available from

NASA Center for Aerospace Information 7121 Standard Drive

Hanover, MD 21076
National Technical Information Service 5285 Port Royal Road Springfield, VA 22100 


\title{
Quantification of Ice Accretions for Icing Scaling Evaluations
}

\author{
Gary A. Ruff \\ National Aeronautics and Space Administration \\ Glenn Research Center \\ Cleveland, Ohio 44135 \\ David N. Anderson \\ Ohio Aerospace Institute \\ Brook Park, Ohio 44142
}

\begin{abstract}
The comparison of ice accretion characteristics is an integral part of aircraft icing research. It is often necessary to compare an ice accretion obtained from a flight test or numerical simulation to one produced in an icing wind tunnel or for validation of an icing scaling method. Traditionally, this has been accomplished by overlaying two-dimensional tracings of ice accretion shapes. This paper addresses the basic question of how to compare ice accretions using more quantitative methods. For simplicity, geometric characteristics of the ice accretions are used for the comparison. One method evaluated is a direct comparison of the percent differences of the geometric measurements. The second method inputs these measurements into a fuzzy inference system to obtain a single measure of the goodness of the comparison. The procedures are demonstrated by comparing ice shapes obtained in the Icing Research Tunnel at NASA Glenn Research Center during recent icing scaling tests. The results demonstrate that this type of analysis is useful in quantifying the similarity of ice accretion shapes and that the procedures should be further developed by expanding the analysis to additional icing data sets.
\end{abstract}

\begin{tabular}{ll}
$L W C$ & \multicolumn{1}{c}{ Nomenclature } \\
$M V D$ & Cloud liquid-water content, $\mathrm{g} / \mathrm{m}^{3}$ \\
$T_{s}$ & Static temperature, ${ }^{\circ} \mathrm{C}$ \\
$T_{t}$ & Total temperature, ${ }^{\circ} \mathrm{C}$ \\
$V$ & Airspeed, $\mathrm{m} / \mathrm{s}$ \\
$W e$ & Weber number, dimensionless \\
$\Delta X_{i}$ & percent difference in characteristic "i” defined \\
$\overline{\Delta X}_{i}$ & by Eq. (1)
\end{tabular}

\section{Introduction and Motivation}

Icing scaling is a test technique that can enhance the capabilities of a ground test facility by allowing similar ice accretions to be formed on geometrically similar objects under different atmospheric and meteorological conditions. Test article size scaling produces conditions such that accretions are formed on a subscale model similar to those that would be obtained at full-scale. Test parameter scaling is aimed at increasing the simulation capabilities of test facilities by extending the Mach number, altitude, and/or temperature ranges. Because of the usefulness and, in some cases, absolute necessity, of icing scaling techniques for ground testing, considerable research in this area has been conducted. $^{1-10}$ Accepted verification of icing scaling methodologies that can be applied in a variety of facilities would be very attractive to test facility operators and aircraft manufacturers.

The development of icing scaling methods as well as the improvement of numerical simulations of the ice accretion process $^{11,12}$ requires the comparison of ice accretion characteristics. These ice accretions may have been formed in an icing test facility, during a flight test, or through a numerical simulation of the ice accretion process. The standard procedure is to overlay twodimensional tracings of the ice accretions. ${ }^{5-10}$ Icing researchers evaluate the "goodness" of the comparison based on their knowledge of the variability of test conditions in an icing facility or the details of the computer model used in the simulation. Terms like "good", "fair", and "poor" are frequently used and conclusions about the icing scaling method or computer model are drawn from a sufficient number of "good" or "poor" comparisons in a given data set. Given the inherent variability in the shape of experimental ice accretions, it is often difficult to determine whether a modification to a scaling method or numerical simulation produces a significant improvement in the ice accretion. In icing scaling, for example, similarly good results are occasionally achieved when conflicting icing scaling methods are applied. Continued development of icing scaling methods and numerical simulations of the ice accretion process depends greatly on our ability to obtain statistically-significant data concerning the comparison of ice accretions.

It is not only the icing researchers who need to compare ice accretion characteristics. Test facility operators and users are frequently concerned with inter- and intra- 
facility comparisons of ice accretions to evaluate facility standardization and icing testing procedures. While uniformity in calibration procedures between facilities helps to achieve standardization, the final test will be whether similar ice accretions are produced at identical test conditions. A quantitative method to compare ice accretions is would also be beneficial in this application.

These observations form the motivation for this work. Both ice accretion prediction and icing scaling methods require more objective quantification of their accuracy to be generally accepted. The ability to quantitatively compare ice accretion characteristics would also contribute significantly to intra- and inter-facility calibration and standardization. The specific objectives of this project are presented below.

\section{Objective}

The purpose of this paper is to investigate two approaches to quantitatively answer the question "How well do two ice accretions compare?" The ability to quantify the goodness of a comparison would allow more objective and easily substantiated conclusions to be drawn from a set of icing data. This work was performed in the context of comparing two icing scaling methods although similar comparisons are required in other areas of aircraft icing analysis and testing. This paper begins with a description of the methods to be used to compare results, followed by a presentation of the experimental methods used to obtain the ice accretions. The ability of the methods to objectively compare ice accretions and, thus, ice accretion scaling methods will be evaluated.

\section{Quantitative Analysis of Ice Shape Features}

In this section, the quantitative analysis of the ice accretions will be described. This will begin by defining the parameters to be quantified and continue with a discussion of the quantification methods. Finally, examples of ice accretions that do and do not compare well will be presented to help with the interpretation of data to be presented later.

\section{Parameters to be Quantified}

In general, previous evaluations of icing scaling methods have been based solely on comparing twodimensional tracings of the ice accretion. ${ }^{5-10}$ However, what constitutes an acceptably scaled ice accretion also depends on the purpose of the test. In aerodynamic tests, it is most critical that the sub-scale accretion has the same lift and drag coefficients as the full-scale. In other applications, parameters such the width or mass of the accretion is most important. In still others, the critical parameter may be the mass of ice shed.
Unfortunately, the data required to make comparisons of any parameter other than ice accretion shape is rather limited. Therefore, the geometric characteristics of an ice shape will be used in this study for the purpose of evaluating the comparison techniques. If found promising, additional parameters could be included in the analysis as they are available.

The geometric characteristics of a typical ice accretion that were identified as being representative of its overall shape are shown in Fig. 1. These include the (1) thickness of the ice accretion at the stagnation point, (2) maximum thickness, (3) maximum width of the ice accretion, (4) impingement width, (5) horn length, and (6) horn angle. These characteristics were measured by first scanning the original ice tracing made during the test and then analyzing the digitized image on the computer. Measurements of the ice accretion parameters were made by hand in this study. The repeatability and subjectivity of these measurements will be addressed in a later section. This technique could be at least partially automated once the merits of this analysis are demonstrated.

For each pair of ice accretions to be compared, the nondimensional percent difference between each of the six measured geometric characteristics was calculated using

$$
\Delta X_{i}=\left|\frac{X_{S}-X_{R}}{X_{R}}\right| \times 100 \%
$$

where $X_{i}$ is the $i^{\text {th }}$ geometric characteristic. Note that the absolute value of the ratio is specified. The subscript $S$ denotes a dimension from the scaled ice accretion while the subscript $R$ denotes a dimension from the reference ice accretion. When comparing ice shapes formed from repeat icing conditions, the denominator in Eq. (1) was taken to be the average of the two dimensions. Therefore, each pair of ice accretions to be compared resulted in a set of six $\Delta X_{i}$ percentages that quantified that comparison.

\section{Methods of Comparison}

Unfortunately, the values of the $\Delta X_{i}$ from a single pair of ice accretions are of no more value to making a comparison than simply overlaying the ice shape tracings. Two methods were investigated to allow more objective and statistically-significant comparisons to be made. Both methods are based on combining the $\Delta X_{i}$ for pairs of ice accretions in a set of data. The first method is a direct averaging of the $\Delta X_{i}$. Specifically, if ten pairs of conditions were run to evaluate a specific icing scaling method, the ten $\Delta X_{i}$ for each geometric characteristic would be averaged to obtain a single 
value. The set of six averaged $\Delta X_{i}$, the $\overline{\Delta X_{i}}$, would then represent the comparison of the ten conditions. An average of these six $\overline{\Delta X_{i}}$ could also be calculated to obtain a single measure of the goodness of the comparison. The performance of this method will be evaluated later. The second method of comparison to be investigated applies the concepts of fuzzy logic to evaluate the $\Delta X_{i}$ percentages instead of directly calculating an average.

\section{Fuzzy Inference Methods}

When comparing the goodness of ice accretions formed using any scaling method, it is typical to use words like poor, fair, good, or excellent. Unfortunately, the distinctions between these ratings are very subjective and defined by whoever is making the judgment. A method having more distinct and agreed-upon boundaries would be useful. The methodology of fuzzy inference systems (FIS) was developed specifically for use in control and decision-making processes where the input data is imprecise. A brief discussion of fuzzy logic concepts is given in the following paragraphs.

Zadeh $^{13}$ laid the foundations for fuzzy logic by introducing the concept of partial (or fuzzy) membership in a set, i.e., an element $\mathrm{x}$ can fully belong to a set X, partially belong to it, or not belong to it at all. This is opposed to traditional set theory where elements either belong or don't belong to a set. In a later paper, Zadeh ${ }^{14}$ illustrated the use of linguistic variables, such as "hot", "cold", or "warm" to define the fuzzy sets. It has since been applied to develop control systems and decision-making schemes that, while fairly easy to accomplish manually, are difficult to describe mathematically. One example that is particularly relevant to the current application is the character recognition schemes used by some electronic personal data assistants (PDA). People can look at handwriting and generally can recognize the letters fairly easily. However, it is extremely difficult to write equations that describe the thought process used to identify the letters. The concept behind fuzzy logic is that if one can make decisions and act with high precision when the information is not precise and not numerical, it is possible to develop a control process using the imprecise data. ${ }^{15}$ In the broadest sense, many of the current applications of fuzzy logic can be viewed as computing with words instead of numbers. Although words are less precise, their use is closer to human intuition.

Fuzzy inference methods are implemented in three basic steps: fuzzification, rule evaluation, and defuzzification. These steps will be described as they are applied in this investigation of ice accretion comparison methods. It is not practical to discuss all of the nuances of a fuzzy inference system in this paper.
Instead, we will develop the methodology as it applies to the current application. Information on fuzzy logic can be found in various texts. ${ }^{15-18}$

Fuzzification-The fuzzification step of the ice accretion fuzzy inference system (FIS) defines the degree of membership (DOM) a specific value of the $\Delta X_{i}$ has to GOOD, FAIR or POOR sets defined using membership functions. As a group, the terms GOOD, FAIR, and POOR are called antecedents. The selection of the functions to define these sets is arbitrary and based on the desired characteristics of the FIS. In the current application, the following requirements were defined:

1. The percent differences range from 0 to $50 \%$ (differences greater than $50 \%$ will be set to that value).

2. Percent differences less than approximately 5\% should yield approximately the same degree of membership.

3. The sensitivity of the membership functions should be approximately linear over the entire range of percent differences.

Three gaussian membership functions for the linguistic terms GOOD, FAIR and POOR were defined based on the fractional values of $\Delta X_{i}$ (instead of percentages) and are shown in Fig. 2. The mean values for these functions are $0.0,0.25$, and 0.50 , respectively. The standard deviation for the GOOD and POOR functions is 0.085 while that for the FAIR function is 0.065 . The fractional values of $\Delta X_{i}$ are on the $\mathrm{x}$-axis while the DOM ranging from 0.0 to 1.0 is shown on the $y$-axis. Of course, a DOM of 0.0 indicates omission from the set while a DOM of 1.0 represents complete membership. As shown in Fig. 2, a vertical line drawn at $\Delta X_{i}=0.175(17.5 \%)$ intersects both the GOOD and FAIR curves. Horizontal lines drawn to the y-axis shows that this value belongs to the GOOD set to degree 0.12 and to the FAIR set to degree 0.51 . For any comparison of two ice accretions, the six $\Delta X_{i}$ were evaluated using these membership functions to yield the degree of membership to one of the three sets: GOOD, FAIR, or POOR. All six $\Delta X_{i}$ used the membership functions shown in Fig. 2.

Rule Evaluation-The rule base of an FIS contains the knowledge or experience of an evaluator or "expert." A rule block is defined in terms of IF-THEN statements and is where the "linguistic calculations" take place. The general form for rules in the current system is If [condition $\mathrm{x}$ ] and [condition $\mathrm{y}$ ] then [result $\mathrm{z}]$. "Conditions $\mathrm{x}$ and $\mathrm{y}$ " are the antecedents (GOOD, FAIR, and POOR, in this case) while the "result z" is 
called a consequent. The rule set applied in this ice accretion FIS is shown in Table 1 . Note that the rules are divided into three blocks, one block each for the thickness, width, and horn measurements.

The four consequent sets used in this application are POOR, FAIR, GOOD, and EXCELLENT and are defined using triangular membership functions, as shown in Fig. 3. As before, the degree of membership is shown on the y-axis and ranges from 0.0 to 1.0. The $\mathrm{x}$-axis represents the FIS output that will be a measure of the goodness of the ice shape comparison. The centroid of the functions shown in Fig. 3 is located at $0,33.33,66.67$, and 100 on FIS output scale. Note that the goodness scale ranges from -16.67 to 116.67 . This was done so that the POOR and EXCELLENT functions would be symmetric about 0 and 100 , respectively. The output from this FIS is a number between 0 and 100 with 100 representing perfect agreement between the two ice shapes.

One important feature to remember about rule sets is that multiple rules are applied for any one set of conditions. Figure 4 shows a fuzzy inference diagram for the system being constructed and illustrates the operation of the rule block. Each of the thickness rules listed in Table 1 form a row of this diagram. The antecedents and consequents used in the rules are the columns. The upper nine cells show the membership functions that apply to each rule. Instead of stating a rule verbally as in Table 1 , this diagram describes it pictorially. For example, compare Rule 1 in Table 1 and Rule 1 in Fig. 4. If the maximum thickness is POOR and the stagnation thickness is POOR, then the thickness is POOR. The POOR membership functions for the maximum and stagnation thickness are shown, as well as the POOR output function for thickness. Each of the thickness rules can be similarly identified in this diagram. The condition illustrated is when both $\Delta X_{\text {max_thick }}$ and $\Delta X_{\text {stag_thick }}=0.15$. The vertical line in the first and second columns intersects the GOOD and FAIR membership functions. The height of the darkened portion of each function indicates the degree of membership. Rules 5, 6, 8, and 9 apply or "fire" for this combination of inputs. Rule 5 contributes to the FAIR thickness consequent, Rules 6 and 8 to the GOOD consequent, and Rule 9 to the EXCELLENT consequent. Note that the degree of membership in the consequent is the minimum of the memberships of either of the two antecedents forming that rule. For example, in Rule 4 , even though $\Delta X_{\text {max thick }}$ belongs to the FAIR set, there is zero membership in the POOR thickness consequent because $\Delta X_{\text {stag } \text { thick }}$ has zero membership in the POOR antecedent (second column).
Defuzzification-Defuzzification is the next step in the application of the FIS. This is where the fuzzy values obtained from the rule evaluation are combined to obtain a single number to be output from the FIS. The application of the defuzzification process is also illustrated in Fig. 4. The cell at the bottom of the righthand column shows the combination (or aggregation) of the four rules that fired in this example. If only one rule applies for a given consequent, that consequent is brought directly down into the aggregation at the bottom of the third column. When more than two rules apply for a specific consequence (both Rules 5 and 6 provide a contribution to the FAIR consequent), the rule providing the maximum contribution is selected. The shaded region in the aggregation cell is the fuzzy output set and represents the contributions to the FAIR, GOOD, and EXCELLENT outputs. The centroid of the shaded region is then calculated to obtain one number that represents the goodness of the comparison. In the current example, with both $\Delta X_{\text {stag_thick }}$ and $\Delta X_{\text {max_thick }}$ equaling 0.15 , a value of 63 is output as the goodness of the thickness comparison.

This is a good point to review what was accomplished by this FIS. The maximum stagnation thickness of a scaled ice accretion differed from the reference by $15 \%$. Because of the membership functions and rules that were defined, this condition had partial membership to sets representing FAIR, GOOD, and EXCELLENT comparisons of ice accretions. This is a very intuitive way to compare ice accretions. One researcher may consider a $15 \%$ difference in geometric shape to be FAIR while another might consider that to be GOOD. The FIS uses this inexact information to output a single goodness parameter.

Recall that Table 1 showed three rule blocks, one each for thickness, width, and horn parameters. The procedure illustrated in Fig. 4 was performed for the thickness, width, and horn blocks resulting in an FIS output for each block. Formally, this is a 6 input-3 output fuzzy inference system which was applied to each pair of icing conditions compared. These three values were then averaged to produce a single goodness parameter for each comparison of a pair of ice accretions.

Goodness of Comparison Scale-Using the fuzzy inference system defined above, we can produce a pictorial scale for the comparison of ice shapes. Figures 5 to 7 show comparisons of three pairs of ice accretions formed on a NACA 0012 airfoil and the output from the fuzzy inference system. Shown in these figures are comparisons for fuzzy outputs of 99.3, 53.6, and 3.8. 
Recall that the larger the output from the fuzzy system, the better the comparison. (The test conditions used to form these accretions are given in the Appendix, along with the conditions for all other ice accretions presented in this paper.) Figures 8 and 9 show two additional comparisons of ice accretions formed on circular cylinders. These results yield approximately the same output values as Figs. 5 and 6, respectively. While the geometries and shapes are different, the goodness of the comparison of these two shapes would be judged the same using this method. These results indicate that the current membership functions and rule set are consistent with the traditional subjective comparisons of ice shapes. Furthermore, comparisons yielding the same value of the FIS output parameter are, indeed, approximately the same level of goodness. Therefore, this fuzzy inference set appears adequate for the comparison of ice shapes in this investigation. They may be modified in the future if this fuzzy logic approach appears feasible and additional experience is gained.

The average percent difference and FIS output are observed to be inversely proportional indicating that both methods may yield similar information and be adequate for the comparison of ice accretions.

\section{Experimental Methods}

Tests to validate scaling methods were performed in the NASA Glenn Icing Research Tunnel (IRT). ${ }^{19}$ It is a closed-loop tunnel with refrigeration system which permits control of temperature from -30 to $4{ }^{\circ} \mathrm{C}$. A water-spray system provides a range of liquid-water content and water droplet size which covers a significant portion of the FAA Part 25 Appendix C icing envelope. The test section has dimensions of 1.8 by $2.7 \mathrm{~m}$, and velocities of up to $160 \mathrm{~m} / \mathrm{s}$ are possible. Tests were performed using two-dimensional NACA 0012 airfoils with chords of 53.3, 35.6, and $26.7 \mathrm{~cm}$. Circular cylinders having diameters of 7.6, 5.1, and 2.5 $\mathrm{cm}$ were also used for some conditions. These test articles were mounted vertically across the 1.8-m-span of the IRT test section. The models had a uniform chord over the full span and were unswept. Test conditions were selected to represent reference cases, and the various scaling methods applied to determine the corresponding scale test conditions. Tests were run at both sets of conditions, two-dimensional cuts through the resulting ice accretions were made at the center of the tunnel test section and $20.3 \mathrm{~cm}$ above the centerline, and ice shapes were recorded by tracing the ice outline onto a cardboard template. These tracings were then digitized for computer storage. From these computer files, the shapes were analyzed and compared.

Measurements of the geometric parameters previously identified were made for 72 ice accretions from a data set obtained during icing scaling tests conducted during May 1995. As previously discussed, all twodimensional ice accretion tracings obtained during these tests were digitized and measurements made manually on a computer. All measurements were normalized by the characteristic dimension of the test article so that comparisons could be made between scaled test articles. Pairs of ice shapes were then compared that were obtained (1) at identical icing conditions formed on different days, (2) from the same icing condition at different locations on the twodimensional test article, and (3) for conditions satisfying various scaling relations.

\section{Uncertainty Analysis}

Before applying the methods to compare ice accretions and draw conclusions about scaling methods, we must answer two questions: (1) what error is introduced by the subjectivity of the measurements? and (2) how good can the comparisons be given the inherent variability of ice shapes obtained from identical icing conditions? The answers to these questions will help to interpret the data presented later.

\section{Tunnel Uncertainty}

The two questions posed above are related to the uncertainty in setting conditions in the IRT. Tunnel temperatures, velocities, and spray-bar conditions were recorded at 2-s intervals during each test. Each of the parameters were averaged over the spray period to obtain the reported conditions. Considering the variations during the run as well as possible instrument error, the total uncertainty in temperature was estimated to be about $\pm 2.5^{\circ} \mathrm{C}\left(4.5^{\circ} \mathrm{F}\right)$, in velocity, less than $\pm 4 \%$, in LWC, less than $\pm 2.2 \%$, and in MVD, less than $\pm 12.7 \%$.

\section{Ice Shape Repeatability}

To be judged acceptable, scaling methods must produce ice shapes that are similar to a reference shape within the typical run-to-run repeatability of ice shapes. This is a benchmark required for any method to quantitatively compare ice accretions. Figures 10a and b show ice shapes obtained at the same tunnel set conditions during icing scaling tests conducted in the IRT during October 1995, December 1995, and June $1996 .^{10}$ Although small differences in ice shape are apparent, the IRT generally gives fairly repeatable ice shapes.

Table 2 shows the percent differences in the geometric characteristics for the conditions compared in Fig. 10. Figure 10a shows very good repeatability between the three conditions. Accordingly, the average percent difference and FIS output was $6.6 \%$ and 93.5, respectively. In Fig. 10b, the comparison between the two conditions is not as good with the stagnation-zone 
thickness, maximum width, horn angle, and impingement width showing greater variability. Horn angle was the least repeatable, primarily because the angles are relatively small and a difference of a few degrees yields a large percent different. The impingement widths differ primarily because of the difficulty in defining the impingement limit from a twodimensional tracing. Fortunately, scaling of droplet trajectories and impingement limits has been verified both computationally and experimentally using temperatures above freezing. ${ }^{20}$ The average percent difference for Fig. 10b was $10.7 \%$ while the FIS output was 80.2. In general, the variation of geometric characteristics for these repeat conditions averaged 7 to $10 \%$.

While Figs. 10a and b demonstrate repeatability from a total of five conditions, averages over a greater number of conditions can be obtained. Also shown in Table 2 are the averages of seven separate comparisons of repeat icing conditions. The average percent difference for these conditions is 8.4 while the FIS output is 83 . These results are consistent with those of Figs. 10a and $\mathrm{b}$ and support this averaging of results to obtain meaningful comparisons. Given this level of variability inherent in ice accretion shapes, this is the best that can be expected from an icing scaling method.

Another aspect of repeatability is the variation of ice accretion along the span of a two-dimensional test article. Measurements from the two-dimensional tracings made at the centerline of the IRT and $20.3 \mathrm{~cm}$ above the centerline were obtained for nine pairs of accretions. The average percent variations and FIS output are shown in the right-hand columns of Table 2. The average percent variation was $10.4 \%$ while the output from the fuzzy inference system was 73. These conditions are observed to vary slightly more than the average run-to-run repeatability of the ice shapes.

\section{Subjectivity of the Measurements}

To address the subjectivity introduced in the measurement of the geometric characteristics, two researchers made independent measurements of the 72 ice tracings in this data set. Each were given the same instructions and diagrams similar to that shown in Fig. 1 to define the dimensions to be measured. After they gained some experience making measurements, they were given additional instructions on how to make measurements for a few of the more subjective conditions. The average percent difference between the two data sets was then calculated for each of the six geometric characteristics and is shown in Table 3. Separate averages were formed for the cylinder and airfoil conditions. The largest differences were observed for the impingement width for the airfoil conditions. This is because of the difficulty in determining the impingement limit when rime feathers are included in the two-dimensional tracing. The impingement limits are better defined for the cylinder conditions because the cylinder is blunter than the airfoil, confining the droplet impingement and ice formation to a narrower region on the surface.

Excluding the impingement limits, the subjectivity in the other measurements is less than $3.1 \%$ for the cylinder while those on the airfoil are approximately $8.2 \%$ percent. The uncertainty due to subjectivity is observed to be less than that due to position and at the same level or slightly below that of icing tunnel repeatability. However, to avoid these questions in the remainder of this paper, the data set from only one researcher, obtained in the fall of 1997, will be used.

\section{Evaluation of the Scaling Methods}

The two scaling methods that were being evaluated in this series of tests was the Ruff (AEDC) method ${ }^{5,8}$ and the constant-We method. ${ }^{9,10}$ These methods use the same set of parameters to scale droplet trajectory, total water catch, freezing fraction, and droplet energy transport term. The differences between these methods are that the Ruff method also maintains the air energy term by adjusting the static pressure at which the tests are conducted. Because the IRT does not provide control over the test-section pressure, a modified form of the Ruff method was used in which the air energy transport terms are not matched. As the name implies, the constant-We method maintains the We between a reference and scaled icing condition. This is not a requirement in the Ruff method. Also, the constant-We method does not hold the air energy term constant. The source and derivation of these scaling parameters will not be discussed in detail in this paper. Additional discussion of these scaling methods can be found in Ruff $^{5}$ and Anderson ${ }^{7-9}$

Normalized measurements of the geometric characteristics were made for sixteen pairs of conditions for each of the modified Ruff and constantWe scaling methods. Each pair of conditions consisted of an ice accretion from a reference condition and one obtained at conditions calculated from the scaling relations. Reference conditions were the same for the modified Ruff and constant-We conditions. Averages of the percent variations and FIS outputs are shown in Table 4. For both scaling methods, the thickness yielded the smallest percent differences and the largest value of the FIS output. The accuracy of the width and horn scaling was approximately the same. Based on both quantification methods for this data set, the modified Ruff method is slightly better than the constant-We number method (63.6 and 56.1, respectively on the FIS comparison scale). The constant-We method appears to be a viable approach to size scaling; however, the success of the modified Ruff 
method, which ignores the $W e$, suggests that all the surface phenomena of importance to the ice accretion process may not be properly simulated simply by holding the We constant. Therefore, the use of the We to represent surface phenomena in ice accretion may need to be re-examined. The variation of the geometric shape for both of these scaling methods is greater than that for either the repeat conditions or the variation due to position on the test article indicating that there is opportunity for improvement in icing scaling by better understanding the ice accretion process.

\section{Discussion of the Quantitative Methods}

The results presented above demonstrate two methods that can be used to compare ice accretions. The results, however, do not necessarily represent the best that can be achieved using current icing scaling technology. This data set was obtained to evaluate several icing conditions that had proved difficult to scale in previous tests. Additional data sets must be evaluated to fully document the current state of icing scaling methods.

Both the percent difference and the fuzzy inference methods were found to yield essentially the same information. This is reasonable because when ice accretion tracings are overlaid, we are essentially evaluating the percent difference albeit somewhat subjectively. We would hope that the FIS would mirror these results. One shortcoming of the percent difference method, however, is that a $15 \%$ difference in the stagnation thickness, for example, may not yield the same degree of agreement as a $15 \%$ difference in horn angle. If these percent differences are averaged, essential information can be lost. By defining appropriate membership functions and rules blocks, a FIS can be constructed to properly correct for these differences. In the application of these methods described in this paper, only six geometric parameters were used. The percent difference method would become even more difficult to apply as the number and types of parameters to be characterized were increased.

\section{Summary and Conclusions}

The objective of this paper was to investigate several methods to quantify the goodness of comparison of ice accretions. These methods must provide quantitative data to answer the question "How well do these two ice accretions compare?" This work was performed in the context of comparing various icing scaling methods; however, similar types of comparisons are required to evaluate how well numerical simulations predict an ice shape or whether the calibration of two test facilities are similar. Two methods were evaluated, both of which were based on measuring geometric characteristics of two-dimensional ice accretion tracings. In one method, a direct comparison of percent differences in the geometric characteristics were made. In the other, a fuzzy inference system was applied to reduce the comparison of the shapes of two ice accretions to a single goodness parameter. Both methods yielded results that aided in the interpretation of the data set. Although slightly more complex in its development, the fuzzy inference method is very robust and worthy of additional study for quantifying the comparison of ice accretions and their characteristics. Other, more specific conclusions drawn from the results presented are given below.

1. Measurement of geometric characteristics from tracings of ice accretions adds a level of subjectivity into the process. This can be reduced to acceptable levels (less than 10\%) when different researchers make these measurements through adequate training and instruction.

2. The average variation of the geometric characteristics for repeat conditions was approximately $8 \%$ which produced an FIS output of 83. The average percent variation for ice accretions formed at the same time but obtained from the centerline and $20.3 \mathrm{~cm}$ above the centerline was about $10 \%$. The output from the ice accretion FIS was 73.

3. Based on the averages of 16 pairs of conditions, the modified Ruff method produced slightly better results than the constant-We method (63.6 and 56.1 respectively on the FIS comparison scale). Compared to the reference condition, the differences in the ice shapes were significantly larger than the repeat conditions, indicating that there is opportunity to improve scaling methodology.

4. The relative success of the modified Ruff method, which ignores the We, suggests that all the surface phenomena of importance to icing may not be properly simulated simply by holding the We constant. Therefore, the use of the We to represent surface phenomena in ice accretion should be reexamined.

5. These results indicate the usefulness of quantitative evaluation in icing scaling studies but don't necessarily represent the capabilities of current icing scaling methods. This type of analysis must be conducted for additional data sets and a larger range of test conditions to draw these conclusions.

Whether the methods investigated in this paper are continued or other methods proposed and evaluated, the comparison of ice accretion characteristics must be placed on stronger statistical basis to draw substantive conclusions from new and existing data sets. 


\section{References}

1. Sibley, E.J. and Smith, R.E., "Model Testing in an Icing Wind Tunnel, Report LR10981, Lockheed Aircraft Corporation, California Division, 1955.

2. Dodson, E.D., "Scale Model Analogy for Icing Tunnel Testing," Document No. D6-7976, Boeing Airplane Company, Transport Division, 1962.

3. Charpin, F. and Fasso, G., "Essais de givrage dans la grande soufflerie de Modane sur maquettes à échelle grandeur et échelle réduite," L'Aeronautique et l'Astronautique, no. 38, 1972; English translation: "Icing Testing in the Large Modane Wind Tunnel on Full Scale and Reduced Scale Models," NASA TM-75373, 1979.

4. Ingelman-Sundberg, M., Trunov, O.K., and Ivaniko, A., "Methods for Prediction of the Influence of Ice on Aircraft Flying Characteristics," Report No. JR-1, Swedish-Soviet Working Group on Flight Safety, 6th Meeting, 1977.

5. Ruff, G.A., "Analysis and Verification of the Icing Scaling Equations," AEDC-TR-85-30, Vol. 1 (Revised), Arnold Engineering Development Center, Tullahoma, TN 1986.

6. Bilanin, A.J., "Proposed Modifications to the Ice Accretion/Icing Scaling Theory," AIAA-88-0203, 1988.

7. Anderson, D.N., "Rime, Mixed- and Glaze-Ice Evaluations of Three Scaling Laws," NASA TM106461 (also AIAA 94-0718), 1994.

8. Anderson, D.N., "Further Evaluation of Traditional Icing Scaling Methods," NASA TM-107140 (also AIAA-96-0633), January 1996.

9. Anderson, D.N., "Evaluation of Constant-WeberNumber Scaling for Icing Tests," NASA TM107141 (also AIAA-96-0636), January 1996.
10. Anderson, D.N. and Ruff, G.A., "Scaling Methods for Simulating Aircraft In-Flight Icing Encounters," Second International Symposium on Scale Modeling, Lexington, KY, June 1997.

11. Wright, W.B., "Update to the NASA Lewis Ice Accretion Prediction Code LEWICE," NASA CR195387, October 1994.

12. Wright, W.B. and Bidwell, C.S., "Additional Improvements to the NASA Lewis Ice Accretion Code LEWICE," NASA TM-106849 (also AIAA95-0752), January 1995.

13. Zadeh, L.A., "Fuzzy Sets," Information and Control, vol. 8, pp. 338-353, 1965.

14. Zadeh, L.A., "Outline of a New Approach to the Analysis of Complex Systems and Decision Processes," IEEE Transactions on Systems, Man, and Cybernetic, vol. 3, no. 1, pp. 28-44, 1973.

15. Fennich, M., "Introduction to Fuzzy Logic," Fuzzy Logic Applications Handbook, Intel Corporation, Mt. Prospect, IL, pp. 11-26, 1994.

16. Mamdani, E.H., "Applications of fuzzy logic to approximate reasoning using linguistic synthesis," IEEE Transactions on Computers, vol. 26, no. 12, pp. 1182-1191, 1977.

17. Kiyoji, A., Sugerro, M., and Hasegawa, T., Fuzzy Systems Theory and Its Applications, Academic Press, Boston, MA, 1992.

18. Wang, L.-X., Adaptive Fuzzy Systems and Control: Design and Stability Analysis, Prentice Hall, New York, NY, 1994.

19. Soeder, R.H., Sheldon, D.W., Andracchio, C.R., Ide, R.F., Spera, D.A., and Lalli, N.M., "NASA Lewis Icing Research Tunnel User Manual," NASA TM-107159, June 1996.

20. Bragg, M.B., "A Similarity Analysis of the Droplet Trajectory Equation," AIAA J., vol. 20, no. 12, pp. 1681-1686, 1982. 
Table 1. Rule Set for the Ice Accretion Fuzzy Inference System

\begin{tabular}{|c|c|c|}
\hline \multicolumn{3}{|c|}{ Width Rules } \\
\hline $\begin{array}{c}\text { IF } \\
\text { Maximum } \\
\text { Width }\end{array}$ & $\begin{array}{c}\text { AND } \\
\text { Impingement } \\
\text { Width }\end{array}$ & $\begin{array}{l}\text { THEN } \\
\text { Width }\end{array}$ \\
\hline poor & poor & poor \\
\hline poor & fair & poor \\
\hline poor & good & poor \\
\hline fair & poor & poor \\
\hline fair & fair & fair \\
\hline fair & good & fair \\
\hline good & poor & good \\
\hline good & fair & good \\
\hline good & good & excellent \\
\hline \multicolumn{3}{|c|}{ Thickness Rules } \\
\hline $\begin{array}{c}\text { IF } \\
\text { Maximum } \\
\text { Thickness }\end{array}$ & $\begin{array}{c}\text { AND } \\
\text { Stagnation } \\
\text { Thickness }\end{array}$ & $\begin{array}{c}\text { THEN } \\
\text { Thickness }\end{array}$ \\
\hline poor & poor & poor \\
\hline poor & fair & poor \\
\hline poor & good & fair \\
\hline fair & poor & poor \\
\hline fair & fair & fair \\
\hline fair & good & good \\
\hline good & poor & fair \\
\hline good & fair & good \\
\hline good & good & excellent \\
\hline \multicolumn{3}{|c|}{ Horn Rules } \\
\hline IF & AND & THEN \\
\hline Horn Angle & Horn Length & Horn \\
\hline poor & poor & poor \\
\hline poor & fair & poor \\
\hline poor & good & fair \\
\hline fair & poor & poor \\
\hline fair & fair & fair \\
\hline fair & good & good \\
\hline good & poor & fair \\
\hline good & fair & good \\
\hline good & good & excellent \\
\hline
\end{tabular}


Table 2. Quantification of Tunnel Repeatability and Effect of Measurement Position on Ice Shape (53.3-cm-chord NACA 0012 Airfoil)

\begin{tabular}{|c|c|c|c|c|c|c|c|c|}
\hline \multirow[b]{2}{*}{ Dimension } & \multicolumn{2}{|c|}{ Repeat (Fig. 10a) } & \multicolumn{2}{|c|}{ Repeat (Fig. 10b) } & \multicolumn{2}{|c|}{ Repeat (Ave of 7) } & \multicolumn{2}{|c|}{ Position (Ave of 9) } \\
\hline & $\begin{array}{c}\text { Percent } \\
\text { Diff }\end{array}$ & FIS & $\begin{array}{c}\text { Percent } \\
\text { Diff }\end{array}$ & FIS & $\begin{array}{c}\text { Percent } \\
\text { Diff }\end{array}$ & FIS & $\begin{array}{c}\text { Percent } \\
\text { Diff }\end{array}$ & FIS \\
\hline Thickness Parameters & & 96.6 & & 90.6 & & 81.6 & & 63.8 \\
\hline Stagnation Thickness & 8.7 & & 11.4 & & 12.8 & & 13.5 & \\
\hline Maximum Thickness & 2.8 & & 5.2 & & 8.2 & & 12.5 & \\
\hline Width Parameters & & 85.9 & & 82.8 & & 81.4 & & 74.3 \\
\hline Impingement Width & 9.4 & & 13.7 & & 3.9 & & 6.5 & \\
\hline Maximum Width & 10.9 & & 6.6 & & 9.1 & & 10.5 & \\
\hline Horn Parameters & & 97.9 & & 67.1 & & 86.1 & & 81.0 \\
\hline Horn Angle & 7.7 & & 23.1 & & 12.4 & & 12.9 & \\
\hline Horn Length & 0.4 & & 4.2 & & 4.1 & & 6.7 & \\
\hline Average & 6.6 & 93.5 & 10.7 & 80.2 & 8.4 & 83.0 & 10.4 & 73.1 \\
\hline
\end{tabular}

Table 3. Quantification of Subjectivity in the Measurements

\begin{tabular}{lcc}
\hline \multicolumn{1}{c}{ Dimension } & Cylinder & $\begin{array}{c}\text { NACA 0012 } \\
\text { Airfoil }\end{array}$ \\
\hline $\begin{array}{l}\text { Thickness Parameters } \\
\quad \text { Stagnation Thickness }\end{array}$ & 3.1 & 10.1 \\
$\quad$ Maximum Thickness & 2.4 & 8.5 \\
Width Parameters & & \\
$\quad$ Impingement Width & 1.6 & 27.1 \\
$\quad$ Maximum Width & 1.5 & 11.5 \\
Horn Parameters & & \\
$\quad$ Horn Angle & 3.0 & 3.4 \\
$\quad$ Horn Length & 0.6 & 7.3 \\
\hline Average & 2.0 & 11.3 \\
\hline
\end{tabular}

Table 4. Quantitative Evaluation of the Modified Ruff and Constant-We Scaling Methods

\begin{tabular}{lcccc}
\hline \multirow{2}{*}{ Dimension } & \multicolumn{2}{c}{ Modified Ruff } & \multicolumn{2}{c}{ constant-We } \\
\cline { 2 - 5 } & $\begin{array}{c}\text { Percent } \\
\text { Diff }\end{array}$ & FIS & $\begin{array}{c}\text { Percent } \\
\text { Diff }\end{array}$ & FIS \\
\hline Thickness Parameters & & 73.0 & & 68.2 \\
$\quad$ Stagnation Thickness & 9.8 & & 10.9 & \\
$\quad \begin{array}{l}\text { Maximum Thickness } \\
\text { Width Parameters }\end{array}$ & 14.4 & & 16.7 & \multirow{2}{*}{49.7} \\
$\quad$ Impingement Width & 20.2 & 60.3 & & \\
$\quad$ Maximum Width & 13.3 & & 15.6 & \\
$\quad$ Horn Parameters & & 57.4 & & 50.4 \\
$\quad$ Horn Angle & 29.0 & & 32.4 & \\
$\quad$ Horn Length & 12.5 & & 14.3 & \\
\hline Average & 16.5 & 63.6 & 19.2 & 56.1 \\
\hline
\end{tabular}




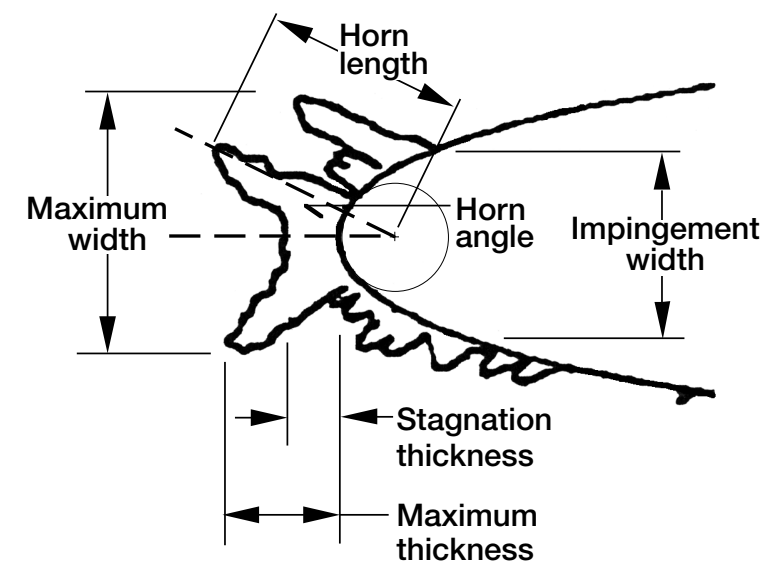

Figure 1. Geometric characteristics of an ice accretion used in the quantitative analysis

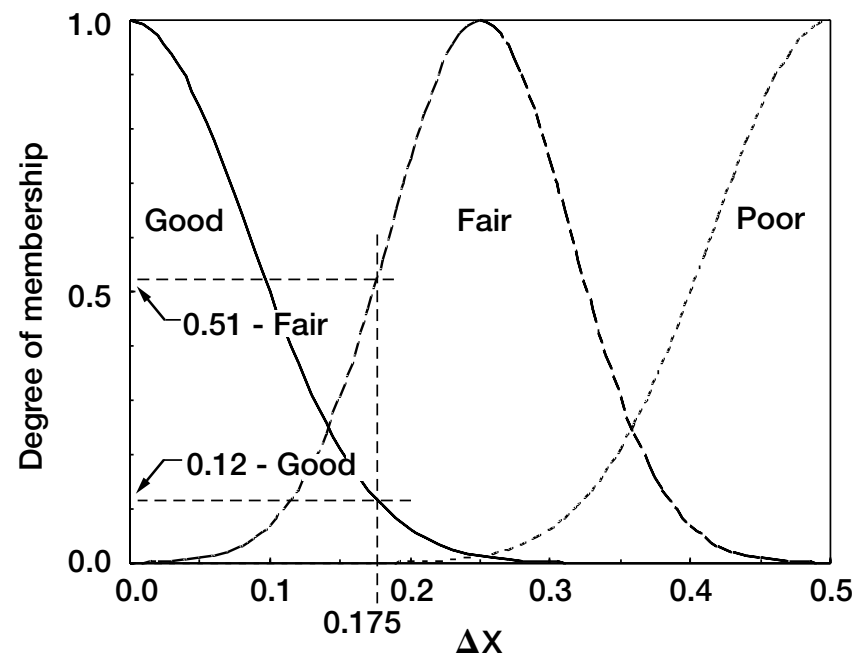

Figure 2. GOOD, FAIR, and POOR antecedent membership functions

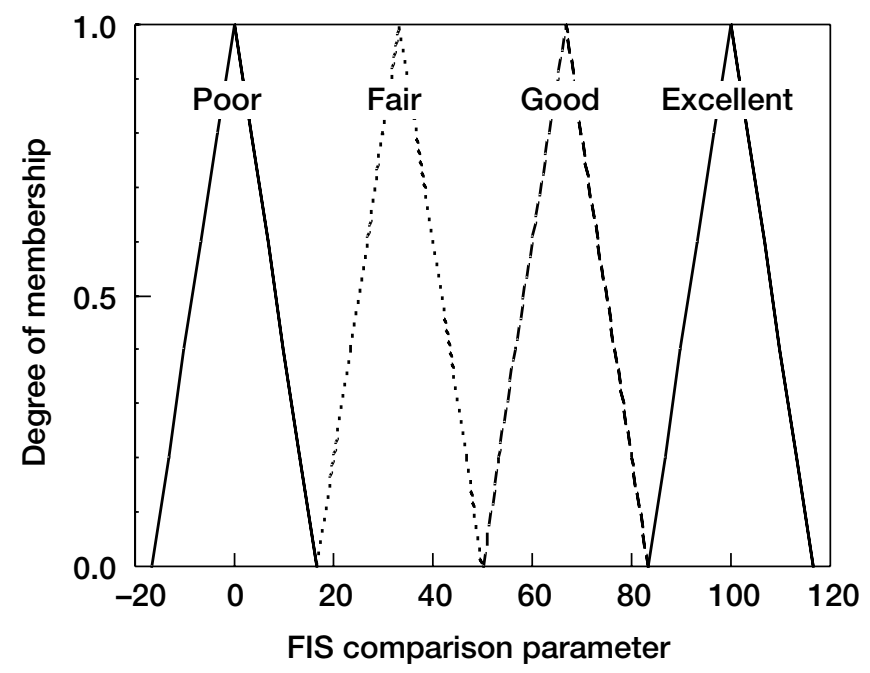

Figure 3. EXCELLENT, GOOD, FAIR, and POOR consequent membership functions 


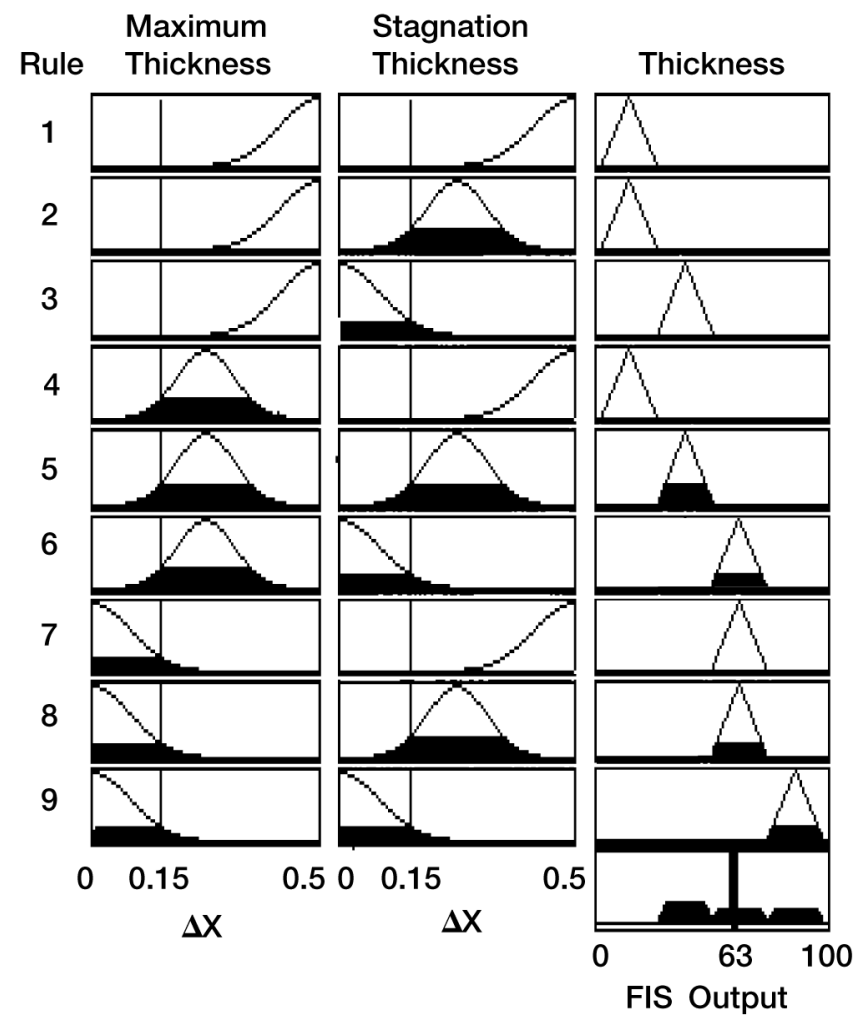

Figure 4. Fuzzy inference diagram for evaluation of the ice accretion thickness

Comparison of Measurements and Fuzzy Results (Conditions 61/62)

\begin{tabular}{|c|c|c|c|}
\hline & Dimension & $\begin{array}{l}\text { Percent } \\
\text { Diff }\end{array}$ & FIS \\
\hline & Thickness Parameters & & 98.7 \\
\hline & Stagnation Thickness & 1.2 & \\
\hline & Maximum Thickness & 6.6 & \\
\hline - Reference & Width Parameters & & 99.7 \\
\hline 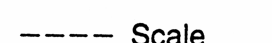 & Impingement Width & 2.1 & \\
\hline & Maximum Width & 1.7 & \\
\hline & Horn Parameters & & 99.5 \\
\hline & Horn Angle & 3.8 & \\
\hline$\pi$ & Horn Length & 1.7 & \\
\hline & Average & 2.9 & 99.3 \\
\hline
\end{tabular}

Figure 5. Comparison of ice shapes for an FIS output of 99.3 (NACA 0012 Airfoil) 


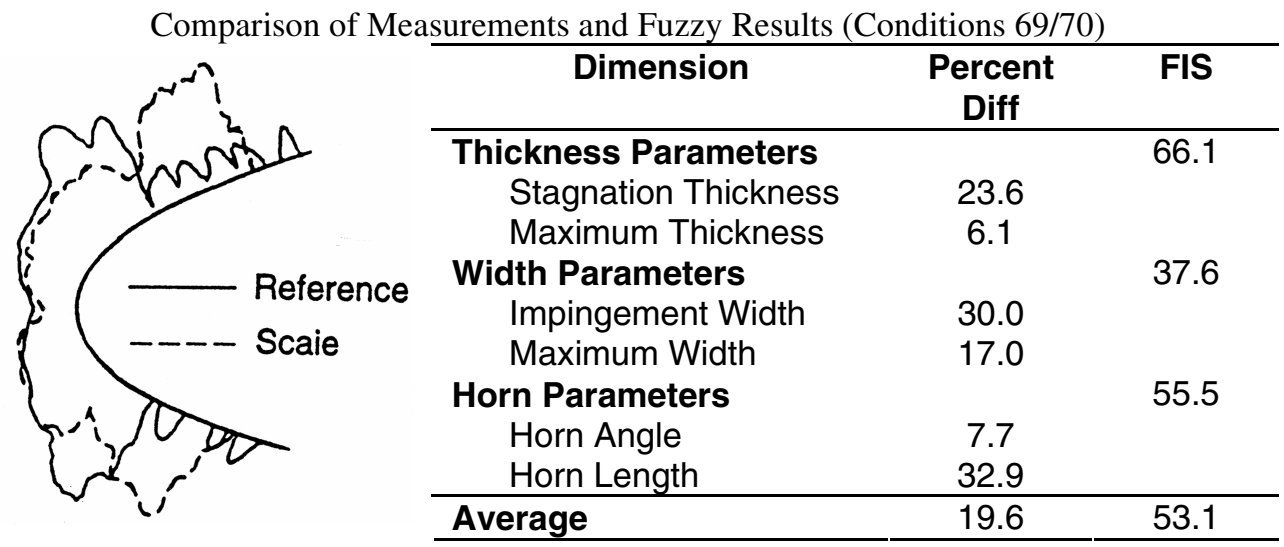

Figure 6. Comparison of ice shapes for an FIS output of 53.1 (NACA 0012 Airfoil)

Comparison of Measurements and Fuzzy Results (Conditions 26/27)

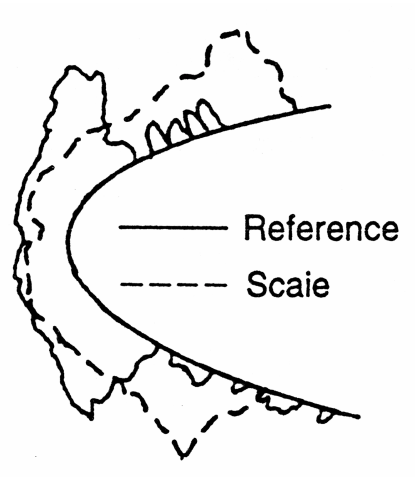

\begin{tabular}{lcc}
\hline \multicolumn{1}{c}{ Dimension } & $\begin{array}{c}\text { Percent } \\
\text { Diff }\end{array}$ & FIS \\
\hline Thickness Parameters & & 4.3 \\
$\quad$ Stagnation Thickness & 40.7 & \\
$\quad$ Maximum Thickness & 27.0 & \\
Width Parameters & & 7.0 \\
$\quad$ Impingement Width & 43.5 & \\
$\quad$ Maximum Width & 20.9 & \\
Horn Parameters & & 0.0 \\
$\quad$ Horn Angle & 69.5 & \\
$\quad$ Horn Length & 50.2 & \\
\hline Average & 42.0 & 3.8 \\
\hline
\end{tabular}

Figure 7. Comparison of ice shapes for an FIS output of 3.8 (NACA 0012 Airfoil)

Comparison of Measurements and Fuzzy Results (Conditions 3/4)

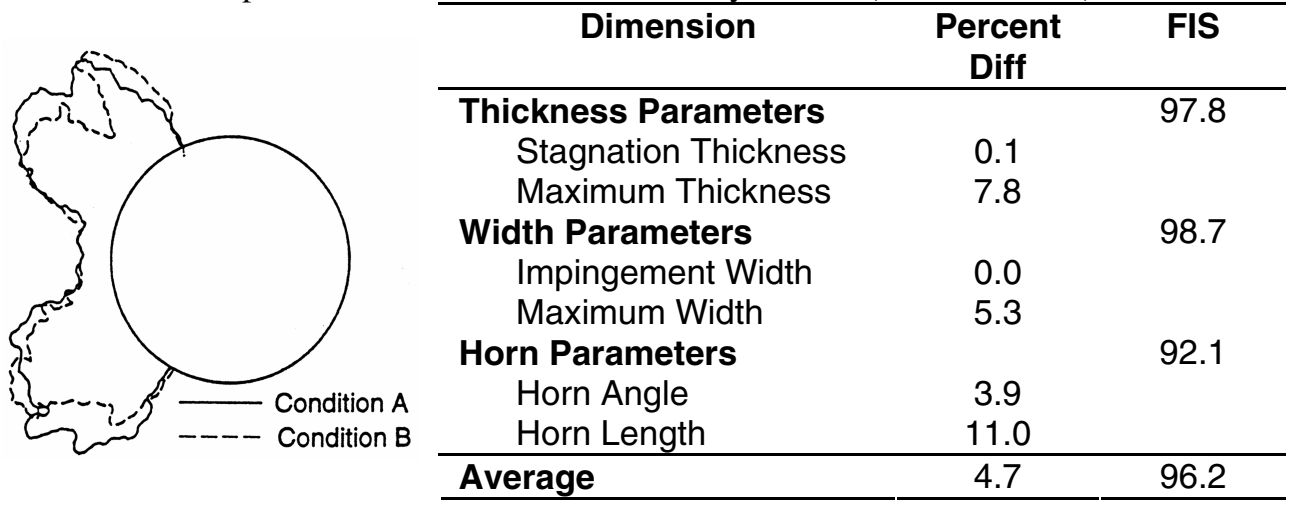

Figure 8. Comparison of ice shapes for an FIS output of 96.2 (Cylinder) 
Comparison of Measurements and Fuzzy Results (Conditions 11/14)

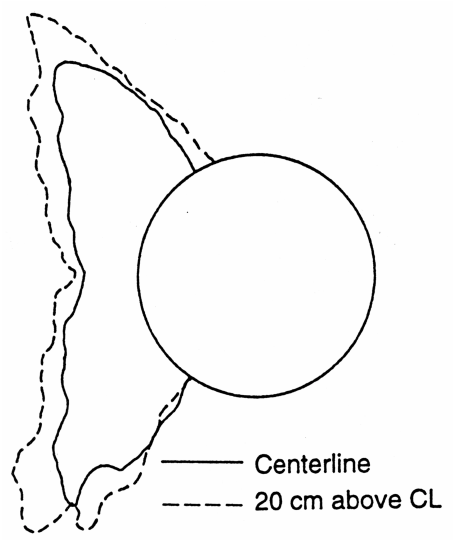

\begin{tabular}{lcc}
\hline \multicolumn{1}{c}{ Dimension } & $\begin{array}{c}\text { Percent } \\
\text { Diff }\end{array}$ & FIS \\
\hline $\begin{array}{l}\text { Thickness Parameters } \\
\quad \text { Stagnation Thickness }\end{array}$ & 20.8 & 9.7 \\
$\quad$ Maximum Thickness & 40.8 & \\
$\begin{array}{l}\text { Width Parameters } \\
\quad \text { Impingement Width }\end{array}$ & 4.8 & 75.1 \\
$\quad$ Maximum Width & 12.8 & \\
$\begin{array}{l}\text { Horn Parameters } \\
\quad \text { Horn Angle }\end{array}$ & 1.2 & 76.0 \\
$\quad$ Horn Length & 16.6 & \\
\hline Average & 16.2 & 53.6 \\
\hline & & \\
\hline
\end{tabular}

Figure 9. Comparison of ice shapes for an FIS output of 53.6 (Cylinders)

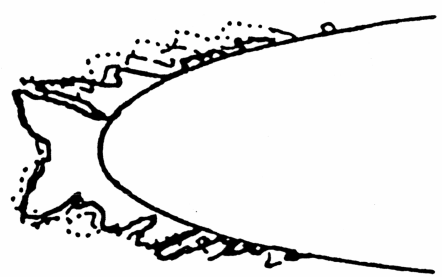

(a)

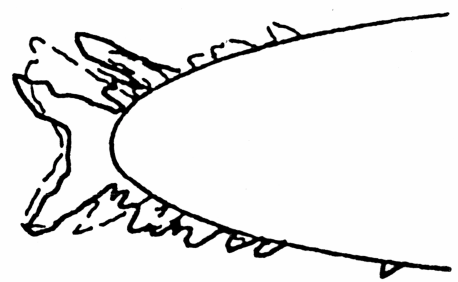

(b)

\begin{tabular}{cccccccc}
\hline Figure & $\begin{array}{c}\text { Chord, } \\
\mathbf{c m}\end{array}$ & $\begin{array}{c}\mathbf{T}_{\mathbf{s}}, \\
{ }^{\circ} \mathbf{C}\end{array}$ & $\begin{array}{c}\mathbf{T}_{\mathbf{t}}, \\
{ }^{\circ} \mathbf{C}\end{array}$ & $\begin{array}{c}\mathbf{V}, \\
\mathbf{m} / \mathbf{s}\end{array}$ & $\begin{array}{c}\text { MVD, } \\
\mathbf{\mu m}\end{array}$ & $\begin{array}{c}\text { LWC, } \\
\mathbf{g} / \mathbf{m}^{3}\end{array}$ & $\begin{array}{c}\text { Time, } \\
\mathbf{m i n}\end{array}$ \\
\hline $10(a)$ & 53.3 & -12 & -9.7 & 67 & 30 & 1.00 & 7.3 \\
\hline $10(b)$ & 53.3 & -9 & -5.1 & 89 & 40 & 0.55 & 10.0 \\
\hline
\end{tabular}

Figure 10. Repeatability of ice shapes (53.3-cm-chord NACA 0012 Airfoil) 


\section{Appendix}

Table A.1. Icing Test Conditions

\begin{tabular}{ccccccccc}
\hline Figure & Mode & $\begin{array}{c}\text { Chord, } \\
\mathbf{c m}\end{array}$ & $\begin{array}{c}\mathbf{T}_{\mathbf{s}}, \\
{ }^{\circ} \mathbf{C}\end{array}$ & $\begin{array}{c}\mathbf{T}_{\mathbf{t}}, \\
{ }^{\circ} \mathbf{C}\end{array}$ & $\begin{array}{c}\mathbf{V}, \\
\mathbf{m} / \mathbf{s}\end{array}$ & $\begin{array}{c}\mathbf{M V D}, \\
\mathbf{\mu m}\end{array}$ & $\begin{array}{c}\mathbf{L W C}, \\
\mathbf{g} / \mathbf{m}^{3}\end{array}$ & $\begin{array}{c}\text { Time, } \\
\mathbf{m i n}\end{array}$ \\
\hline 5 & Reference & 53.3 & -6.7 & -4.4 & 67 & 30 & 1.00 & 7.3 \\
& Scale & 26.7 & -7.2 & -3.3 & 88 & 18 & 1.13 & 2.5 \\
\hline 6 & Reference & 53.3 & -6.7 & -2.8 & 89 & 30 & 0.70 & 7.3 \\
& Scale & 26.7 & -6.7 & -2.8 & 89 & 20 & 0.99 & 2.6 \\
\hline 7 & Reference & 53.3 & -6.7 & -4.4 & 67 & 30 & 1.00 & 7.3 \\
& Scale & 35.6 & -6.7 & -3.8 & 79 & 22 & 1.08 & 3.8 \\
\hline 8 & A & 7.6 & -7.1 & -3.1 & 89 & 23 & 1.25 & 14.2 \\
& B & 7.6 & -7.1 & -3.1 & 89 & 23 & 1.25 & 14.2 \\
\hline 9 & Centerline & 2.5 & -10.1 & -4.9 & 102 & 27 & 1.10 & 4.8 \\
& 20 cm above CL & 2.5 & -10.1 & -4.9 & 102 & 27 & 1.10 & 4.8 \\
\hline $10(\mathrm{a})$ & Repeat & 53.3 & -12 & -9.7 & 67 & 30 & 1.00 & 7.3 \\
\hline $10(\mathrm{~b})$ & Repeat & 53.3 & -9 & -5.1 & 89 & 40 & 0.55 & 10.0 \\
\hline
\end{tabular}




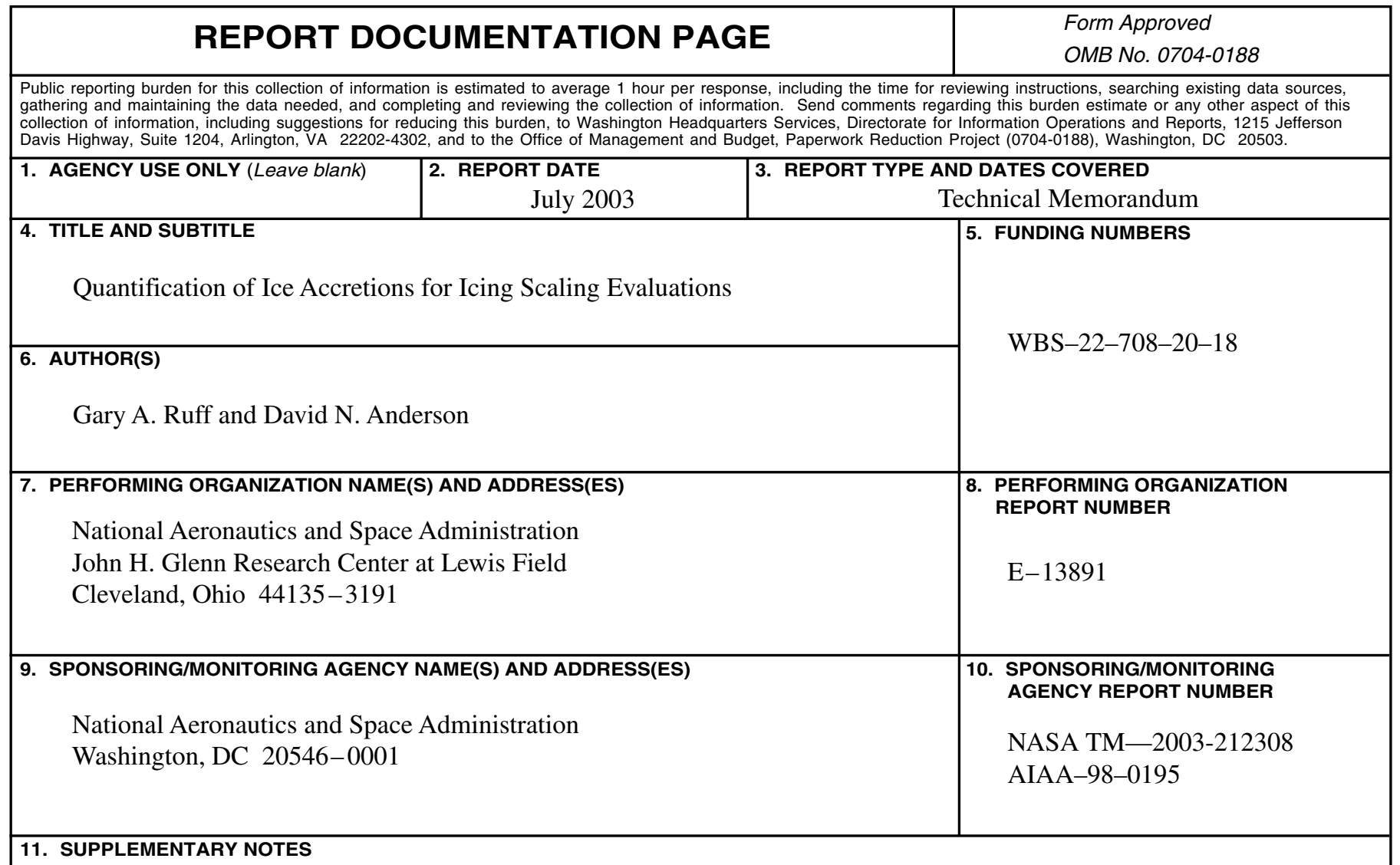

Prepared for the 36th Aerospace Sciences Meeting and Exhibit sponsored by the American Institute of Aeronautics and Astronautics, Reno, Nevada, January 12-15, 1998. Gary A. Ruff, NASA Glenn Research Center; and David N. Anderson, Ohio Aerospace Institute, Brook Park, Ohio 44142. Responsible person, Gary A. Ruff, organization code 6711, 216-433-5697.

12a. DISTRIBUTION/AVAILABILITY STATEMENT 12b. DISTRIBUTION CODE

Unclassified - Unlimited

Subject Categories: 09 and 01

Distribution: Nonstandard

Available electronically at http://gltrs.grc.nasa.gov

This publication is available from the NASA Center for AeroSpace Information, 301-621-0390.

\section{ABSTRACT (Maximum 200 words)}

The comparison of ice accretion characteristics is an integral part of aircraft icing research. It is often necessary to compare an ice accretion obtained from a flight test or numerical simulation to one produced in an icing wind tunnel or for validation of an icing scaling method. Traditionally, this has been accomplished by overlaying two-dimensional tracings of ice accretion shapes. This paper addresses the basic question of how to compare ice accretions using more quantitative methods. For simplicity, geometric characteristics of the ice accretions are used for the comparison. One method evaluated is a direct comparison of the percent differences of the geometric measurements. The second method inputs these measurements into a fuzzy inference system to obtain a single measure of the goodness of the comparison. The procedures are demonstrated by comparing ice shapes obtained in the Icing Research Tunnel at NASA Glenn Research Center during recent icing scaling tests. The results demonstrate that this type of analysis is useful in quantifying the similarity of ice accretion shapes and that the procedures should be further developed by expanding the analysis to additional icing data sets.

\section{SUBJECT TERMS}

Aircraft icing; Icing scaling; Fuzzy logic

\begin{tabular}{|c|c|c|c|}
\hline $\begin{array}{c}\text { 17. SECURITY CLASSIFICATION } \\
\text { OF REPORT } \\
\text { Unclassified }\end{array}$ & $\begin{array}{c}\text { 18. SECURITY CLASSIFICATION } \\
\text { OF THIS PAGE } \\
\text { Unclassified }\end{array}$ & $\begin{array}{c}\text { 19. SECURITY CLASSIFICATION } \\
\text { OF ABSTRACT } \\
\text { Unclassified }\end{array}$ \\
\hline
\end{tabular}

